\title{
Economia laranja e comunicação: uma nova partilha do valor da informação na era da criatividade
}

Straw economics and communication:

a new distribution of the value of information in the era of creativity

Economía naranja y comunicación:

una nueva partición del valor de la información en la era da creatividad

Bárbara Martins Zaganelli

- Doutoranda em Ciência da Informação no Instituto Brasileiro de Informação em Ciência e Tecnologia (IBICT) em parceria com a Universidade Federal do Rio de Janeiro (UFRJ)

- Mestre em Políticas Sociais pela Universidade Estadual do Norte Fluminense "Darcy Ribeiro" (Uenf)

- Especialista em Estudos de Imagem e Mídia pela Universidade Cândido Mendes (Ucam)

- Licenciada em História e Português pela Faculdade Capixaba de Nova Venécia (Univen)

- Bacharel em Comunicação Social - Jornalismo pela Faculdades Integradas Espírito-Santenses (Faesa)

- E-mail: barbarazaganelli@hotmail.com

Marcelo Carlos Gantos

- Realizou estagio de pós-doutoramento na Escuela de Estudios Hispanamericanos (EEHA), Sevitha, Espanha

- $\quad$ Doutor em História Social da América pela Universidade Federal Fluminense (UFF)

- Mestre em História Urbana pela UFF

- Graduado em História pela Universidad Nacional de Mar del Plata

- Professor associado do Laboratório de Estudos do Espaço Antropico da Universidade Estadual do Norte Fluminense "Darcy Ribeiro" (UENF)

- Professor orientador do Programa de Pós-Graduação em Politicas Sociais UENF-CAPES

- E-mail: mcgantos@gmail.com 


\section{Resumo}

Diante da crise das formas tradicionais de comunicação e o boom das redes sociais e mídias alternativas pautadas pela convergência digital, discute o processo de (re)arranjo no cenário da comunicação e os atuais desafios da mídia pensando em uma nova forma de partilha da informação pelo viés da economia laranja, isto é, pela economia da cultura e criatividade. Espera-se contribuir para a análise do impacto da economia laranja no cenário da comunicação, os avanços e impasses.

\section{PALAVRAS-CHAVE: COMUNICAÇÃO SOCIAL・ECONOMIA CRIATIVA・ECONOMIA LARANJA・CONHECIMENTO・INFORMAÇ̃̃O.}

\section{Abstract}

In view of the crisis of traditional forms of communication and the boom of social networking and alternative media based on digital convergence, one discusses the process of (re)arrangement of the scenario of communication and the current challenges of the media, thinking about a new way for distribution of the information under the straw economics bias, i.e., by the economics of culture and creativity. One expects to contribute to an analysis of the impact of straw economics on the communications scenario, the progresses and the impasses.

\section{KEYWORDS: SOCIAL COMMUNICATION • CREATIVE ECONOMICS • STRAW ECONOMICS • KNOWLEDGE・INFORMATION.}

\section{Resumen}

Frente a la crisis de las formas tradicionales de comunicación y el boom de las redes sociales y mídias alternativas pautadas por la convergencia digital, se discute el proceso de (re)configuración del escenário de la comunicación y los actuales desafios de la midia pensando en una nueva forma de compartir la informação en el contexto de una economia naranja, es decir, por la economía de la cultura y creatividad. Se espera contribuir para el análisis del impacto de la emergência de la economia naranja en el esceneario de la comunicación, identificando sus avances e impases. 
A economia laranja é um precedente na economia criativa, um conceito desenvolvido por John Howkins, autor de The creative economy: how people make money from ideas (2001) compreendendo os seguintes setores: arquitetura, artes visuais e performativas, artesanato, cinema, design, pesquisa, publicação e desenvolvimento de jogos e brinquedos, moda, música, publicidade, software, televisão, rádio e jogos de vídeo.

A expressão economia laranja foi proposta em uma pesquisa do Banco Interamericano de Desenvolvimento (BID), compilada em 240 páginas por Felipe Buitrago e Iván Duque, em La economía naranja: una oportunidad infinita'. A obra, baseada em um estudo longitudinal sobre economia criativa e inovação na América Latina e no Caribe, sistematiza e analisa uma série de informações e dados procedentes da Organização Mundial da Propriedade Intelectual (Ompi), da consultoria Oxford Economics e da Conferência das Nações Unidas sobre Comércio e Desenvolvimento (Unctad).

Buitrago e Duque (2013) propõem o termo economia laranja para identificar a economia da cultura e da criatividade. Isto é, o conjunto de atividades que permitam ideias ligadas à bens e serviços culturais, cujo valor é determinado pelo conteúdo da propriedade intelectual.

Apesar da relação complexa entre a economia e a cultura, a pesquisa do BID, apoiada por relatórios da Organização Mundial da Propriedade Intelectual ou da Conferencia Conferência das Nações Unidas sobre Comércio e Desenvolvimento, dimensiona o valor econômico e social da economia criativa para o desenvolvimento regional. A economia laranja seria a terceira maior economia do continente (cerca de 2 bilhões de dólares), o sétimo exportador de bens e serviços (87 milhões de dólares) e quarto lugar na geração de empregos (23,3 milhões de trabalhadores).

Por essa razão, diante do peso da economia laranja na América Latina, parece otimista pensar na partilha da informação tomando por base a economia da cultura e da criatividade. Por essa perspectiva, a nova equação da informação deve conter valores advindos da diversidade de nicho e potencial da economia laranja na região, além da riqueza no patrimônio cultural e linguístico.

0 documento do BID sugere discussões centradas em sete princípios para que haja o desenvolvimento da economia laranja: informações; instituições; indústria; infraestrutura; integração; inclusão; e inspiração. Entre os apontamentos, destaca-se que a deficiência de informações é o pecado original da economia laranja, uma combinação de ignorância mútua entre cultura e economia.

Mais do que gerar informações sobre as indústrias culturais e disponibilizá-las ao público, o debate que propomos aqui extrapola a importância do acesso à informação e chama a atenção para o compartilhamento da informação. Uma nova partilha da informação que estimule a criatividade, talento, conectividade e herança cultural.

Para isso, tentaremos circunscrever mais precisamente os termos, concatenando e contextualizando as ideias do francês Jacques Rancière, pela teoria da "partilha do sensível". A partir dessa perspectiva, tentarmos encontrar um conjunto de noções que se interliguem e expressem reflexões como possibilidades para a análise do impacto da economia laranja no cenário da comunicação, os avanços e impasses.

1 Disponível em: <http://publications.iadb.org/handle/11319/3659?locale-attribute=en>. Acesso em: 10 jul. 2015. 


\section{ECONOMIA CRIATIVA: UMA OPORTUNIDADE NA CRISE}

A economia criativa surgiu para resolver um problema e se fortaleceu diante da crise. Foi diante da crise econômica global dos setores tradicionais que a economia criativa tomou projeções maiores no Reino Unido, em 1997. 0 governo britânico fez um estudo para separar os setores que tinham potencial econômico relevante para o país. Assim, chamaram de indústrias criativas as indústrias que têm sua origem na criatividade, habilidade e talento individuais e que apresentam um potencial para a criação de riqueza e empregos por meio da geração e exploração de propriedade intelectual.

0 termo apareceu pela primeira vez em 1994, no projeto do governo australiano "Creative Nation". Objetivava-se fortalecer as artes e, ao mesmo tempo, criar políticas públicas de preservação da herança cultural e do reconhecimento dos aborígenes australianos como elemento relevante da identidade nacional. Assim, os estudos iniciaram-se levando em consideração a relevância do trabalho criativo, sua contribuição para a economia da região e o papel das tecnologias como aliadas da política cultural.

A economia criativa ganhou repercussão na mídia, mais precisamente em 2001, em Londres, quando a revista Business Week trazia o título "The creative economy: the 21st century corporation". 0 termo também apareceu no já mencionado livro The creative economy: how people make money from ideas, de John Howkins, em 2013. Em linhas gerais, o conceito de economia criativa está relacionado intimamente ao desafio de transformar a sociedade em uma economia que tem criatividade, cultura e arte como elementos-chave para o desenvolvimento local, a sustentabilidade econômica e a inclusão cultural.

O BID destaca que a economia criativa "representa uma riqueza enorme baseada em talento, propriedade intelectual, conectividade e, por conseguinte, na herança cultural de nossa região". Em relação às indústrias culturais, aponta que elas compreendem os bens e serviços que tradicionalmente se associam às políticas culturais, os serviços criativos e desportes.

A Conferência das Nações Unidas sobre Comércio e Desenvolvimento (Unctad)² agrupa as indústrias criativas em quatro categorias, que são intrinsecamente inovadoras e promissoras na geração de emprego e renda. São elas: patrimônio cultural (incluindo artesanato, festivais e expressões da cultura tradicional); artes (artes visuais, pintura, escultura e fotografia/artes dramáticas, teatro, dança, ópera, circo, música); mídia (edição e mídia impressa, audiovisual, cinema e rádio); e criações funcionais (design de moda e de interiores, arquitetura, conteúdos digitais, jogos).

Compreendido o exposto, nos debruçaremos sobre o termo proposto por Buitrago e Duque (2013), economia laranja, que precedeu a economia criativa. Ela representa um conjunto de atividades que permitam ideias encadeadas em bens e serviços culturais, cujo valor é determinado pelo seu conteúdo da propriedade intelectual. Em suma, economia laranja é a economia da cultura e criatividade, como veremos a seguir.

\section{O IMPACTO DA ECONOMIA LARANJA NA AMÉRICA LATINA}

A cor laranja é carregada de significados e símbolos. A economia laranja está associada à cultura, criatividade e identidade. Os próprios autores, Buitrago Restrep e Duque Márquez\ (2013), que propõem a economia laranja, explicam que a cor está

2 A Unctad é um órgão da Assembléia Geral da Organização das Nações Unidas (ONU) e tem sido usada pelos países subdesenvolvidos como um grupo de pressão. Mais informações disponíveis em: <http://unctad.org/en/Pages/Home.aspx>. Acesso em: 20 jul. 2015. 
presente na mitologia grega (como Dionísio, o deus do vinho e do teatro, que aparece nas pinturas vestindo laranja), nas religiões orientais (no confucionismo é a cor da transformação, no budismo identifica os monges, no hinduísmo é a cor das roupas usadas pelos sadhu, que são homens santos que viajam pelo mundo, no chakra representa o abdômen, que é em si o centro criativo do indivíduo) e nos povos nativos da América do Norte, onde é a cor da aprendizagem e da liderança. É também uma cor associada ao fogo (as metáforas do fogo criativo e do fogo do amor).

0 peso e a força da economia laranja foram dimensionados pela pesquisa do BID, que contribui para uma análise mais quantitativa do impacto da economia criativa na economia mundial, principalmente na América Latina e no Caribe. Pelos dados de 2013, curiosamente, enquanto a economia laranja produz anualmente cerca de 4,3 milhões de dólares no mundo, a América Latina e o Caribe produzem apenas 175 mil dólares desse total.

Outro dado interessante é que, de acordo com a Unctad, entre 2002 e 2011 as exportações de bens e serviços criativos cresceram 134\% no mundo. Um total de 646 mil dólares de unidades vendidas. Dito em outras palavras: foi considerado o quinto bem do planeta. Mas, para a nossa preocupação no Brasil, foram mobilizados na América Latina e no Caribe apenas cerca de 19 mil dólares.

Sem duvidas, os números poderiam ser bem mais prósperos, tendo em vista a diversidade do nicho e potencial da economia Laranja na América Latina. Basta pensar em todos os bens da indústria criativa que poderiam ser aproveitados de maneira mais rentável, como turismo, novela, cinema, festival, carnaval, arquitetura, música, publicidade, joias, entre outros. Isso sem contar com o patrimônio cultural e linguístico.

Existem diversas informações que poderiam ser aqui destacadas para demonstrar a relevância da economia laranja, não só por ser rentável, mas por ser sustentável e contribuir para o desenvolvimento da região. Mas, cabe ressaltar que, em termos de emprego, um dos grandes desafios contemporâneos, o BID aponta que, em 2011, de quase 3,27 milhões de trabalhadores no mundo, a economia laranja gerou 144 milhões de oportunidades de trabalho, sendo que 10 milhões de empregos foram distribuídos na América Latina.

No que diz respeito aos produtos gerados pela indústria cultural, o estudo aponta que só o Carnaval do Rio de Janeiro recebeu 850 mil visitantes em 2012, que consumiram 828 milhões de dólares. Isso equivale a mais de 100 horas de vídeo carregadas a cada minuto para o YouTube, acumulando, em agosto de 2013, 6 milhões de horas de vídeo visitado por mais de 1 milhão de pessoas.

Podemos, portanto, constatar que a conectividade e a colaboração contribuem para a taxa de crescimento da economia laranja, uma vez que o comércio de serviços criativos está crescendo 70\% mais rápido do que a de bens criativos, e essas transações ocorrem cada vez mais pela internet. Sobre isso o BID lembra que, no que se refere ao telefone, foram 35 anos de marketing para que os lares norte-americanos tivessem um. A televisão levou 26 anos para chegar a esse percentual, o rádio, 22 anos; e os computadores, Internet 7 e Gmail, Facebook, Twitter, Instagram, Linkedin e discos rígidos emoraram dois anos.

Após essa síntese, fica evidente que as indústrias culturais e de entretenimento são excelentes oportunidades para estabelecer uma nova economia. Mas, ao mesmo tempo em que são numerosas as vantagens de promover a arte e a cultura como um espaço para desenvolvimento da região e a inclusão social, questiona-se como a economia laranja pode ser estimulada. 
O BID apresenta ideias e ferramentas para consolidar uma indústria de criatividade baseada em diversas características culturais da América Latina, que, como já apontamos antes, estão centradas em sete questões: informações, instituições, indústria, infra-estrutura, integração, inclusão social e inspiração. Para este trabalho, iremos nos concentrar nos itens informacionais e de inclusão social.

Da perspectiva da inclusão social, é interessante observar que a economia laranja constrói o tecido social a partir da capacidade de evidenciar identidades alternativas para as diferentes minorias como agentes de desenvolvimento econômico. Os empregos gerados são com baixo investimento, por meio de microcréditos e projetos em parcerias com a comunidade. Assim, ao misturar diferentes sujeitos em torno de um propósito em comum, a economia laranja atenua assimetrias tão grandes em nosso país por motivos óbvios, que são históricos, políticos, econômicos e sociais.

A grande questão que o BID coloca mesmo como a primeira no ranking listado por ele é o déficit de informação. A pesquisa chama a atenção para a importância de gerar informações sobre as indústrias culturais, que fiquem disponíveis para 0 público, para ajudar a atenuar o fosso das posições ideológicas entre criadores/artistas e o mercado/economia.

Nós vamos um pouco mais adiante e pensaremos neste espaço como a informação deve ser partilhada. Para isso, iremos contextualizar e levantar algumas questões em relação à comunicação, pela "teoria da partilha do sensível".

\section{A PARTILHA DO SENSÍVEL DA INFORMAÇÃO}

Inspirado nas ideias de Foucault sobre as camadas do saber, subjetivação e poder presentes na ordem do discurso, Rancière (2010) pensou em um sistema de evidências sensíveis: a existência de "um comum" e as divisões nele existentes. Essa contradição lógica, conhecida como teoria da "partilha do sensível", propõe como as coisas podem ser pensadas e se tornar visíveis e dizíveis.

A teoria da partilha do sensível compreende a sociedade como uma comunidade de partilha e intervalos, em que o "ser em comum" é definido pelas relações que ligam os sujeitos sem separá-los. Segundo Rancière (2010, pág. 15-16),

\footnotetext{
uma partilha do comum fixa portanto, ao mesmo tempo, um comum partilhado e partes exclusivas. Essa repartição das partes e dos lugares se funda numa partilha de espaços, tempos e tipos de atividades que determina propriamente a maneira como um comum se presta à participação e como uns e outros tomam parte nessa partilha. 0 cidadão, diz Aristóteles, é quem toma parte no fato de governar e ser governado. Mas uma outra forma de partilha precede esse tomar parte: aquela que determina os que tomam parte. (...) A partilha do sensível faz ver quem pode tomar parte no comum em função daquilo que faz, do tempo e do espaço que essa atividade exerce.
}

0 mesmo ocorre quando uma informação é partilhada. Nesse caso, o cidadão é aquele que tem informação qualificada para poder governar e ser governado.

Um dos pontos-chave, na nova partilha da informação, é pensar pela partilha que gere capacidade de produzir conhecimento, saber e produção de uma nova informação qualificada, este último talvez o item mais importante de todos na nova equação do valor da informação. Dito em outras palavras: que a informação, uma vez partilhada, seja capaz de produzir uma nova informação pelos sujeitos envolvidos.

Nesse sentido, é preciso pensar quem pode tomar parte do "em comum" e quem determina os que podem tomar parte em função do que se faz, do tempo e do espaço que essa atividade exerce. Sob essa perspectiva, Barreto (1994) observa 
uma realidade fragmentada por desajustes sociais, econômicos e políticos e, mesmo, que a realidade pode ser vista como micronações isoladas por suas diferenças. "São entidades orgânicas, com o forte sentimento coletivo, mas que diferem, por exemplo, em condições, grau de instrução, nível de renda, entre outros pontos" (Barreto, 1994).

Assim, a comunidade estaria menos no "em comum" da sociedade. Para Barreto (1994), essa diferenciação de aproximação condiciona a distribuição da informação, o uso e a sua assimilação. Por isso, a sociedade é vista como um campo polêmico e não consensual, em que surgem fissuras na construção de "um comum".

Um mundo "comum" não é nunca simplesmente o ethos, a estadia comum, que resulta da sedimentação de um determinado número de atos entrelaçados. É sempre uma distribuição polêmica das maneiras de ser e das "ocupações" num espaço de possíveis. A partir daí é que se pode colocar a questão da relação entre o "ordinário" do trabalho e a "excepcionalidade" artística (Rancieère, 2010, p. 62 e 63).

A partir das fissuras surgem vozes dos sujeitos envolvidos na construção do "em comum". Podem ser sujeitos desconhecidos ou ignorados. É o caso, por exemplo, quando os indivíduos excluídos do discurso percebem uma injustiça ou desigualdade e por meio da linguagem expõem as suas experiências. Por isso, o ponto de partida para a construção de um discurso não é a igualdade.

Rancière (2010) aponta que os processos de criação de dissensos constituem uma estética que coloca em comunicação regimes separados de expressão.

A palavra "estética" não remete a uma teoria da sensibilidade, do gosto ou do prazer dos amadores da arte. Remete, propriamente, ao modo de ser específico daquilo que pertence à arte, ao modo de ser de seus objetos. No regime estético das artes, as coisas da arte são identificadas por pertencerem a um regime específico do sensível. Esse sensível, subtraído de suas conexões ordinárias, é habitado por uma potência heterogênea, a potência de um pensamento que se tornou ele próprio estranho a si mesmo: produto idêntico ao não-produto, saber transformado em não-saber, logos idêntico a um pathos, intenção do inintencional etc. (Rancière, 2010, p. 32).

A partir do momento em que o "em comum" da informação é dividido, surgem fissuras e dissensos. 0 desacordo na distribuição do sensível, e os modos de sua inclusão, são ações de resistência que buscam encontrar maneiras de transformar o fixo e imutável. Por essa razão, os desentendimentos na partilha da informação promovem a emancipação e a criação de comunidades de partilha. Isto é, ao mesmo tempo, que o dissenso de uma informação compartilhada fratura os sujeitos, faz com que não haja uma separação. Ao contrário, une as vozes.

Visto por esse ângulo, o dissenso da informação, que mostra as fissuras e os fragmentos das ideias do grande corpo social, contribui para a transformação social. Por isso, o pensamento da partilha da informação, que estimule a cultura e a criatividade, deve respeitar, fundamentalmente, tanto os consensos quanto os dissensos.

\section{DESAFIOS E IMPASSES DA INFORMAÇÃO LARANJA NO BRASIL}

Para pensarmos na comunicação no Brasil, pela questão específica da informação, temos que destacar três questões que nos parecem oportunas. A primeira é que as conturbações enfrentadas pelo contemporâneo, em parte pela convergência da mídia para a plataforma digital, abrem um espaço interessante de debate sobre as mudanças na dinâmica da comunicação. Como resposta imediata à crise das mídias tradicionais, como a televisão, o rádio e o impresso, houve um boom das redes sociais e mídias alternativas. Nessa nova cadeia produtiva o principal insumo foi o capital cultural, especialmente a criatividade, inaugurando o que se chama de economia criativa. 
A segunda é que, se por um lado, a crise gerou um ambiente favorável à inovação da comunicação, por outro abriu um horizonte de incertezas em relação ao fazer da comunicação, inclusive sobre o novo perfil de comunicadores e do público em geral. Houve uma mudança no que se pensa sobre as ferramentas, as relações de trabalho e, principalmente, a definição de bens como produto do conhecimento.

Por fim, a terceira é que, em meio a incertezas, como efeito, a interatividade e a colaboração ajudaram a redesenhar um cenário mais promissor para a democratização das informações. Quando tratamos de informação, é fundamental destacar seu potencial transformador quando assimilado, capaz de estimular a participação cidadã. Um cidadão bem informado, que se sente pertencente à comunidade na qual vive e saiba sobre os assuntos relacionados a ela, tem maior possibilidade de participar das agendas políticas e públicas e, se preciso for, tem condições de lutar pelos seus direitos.

Diante desse quadro, coloca-se como questão, mais uma vez, como a informação deve ser partilhada pela perspectiva da economia laranja, o que inclui não só as informações pertinentes ao tema, mas que contêm em si o olhar da cultura e da criatividade. Na verdade, busca-se pensar em novas formas de informações compartilhadas que valorizem o local, estimulem o desenvolvimento da região e superem as barreiras de exclusão, promovendo a capacidade dos vulneráveis na produção de informação.

Enfatiza-se, com isso, que o processo básico da informação não é a troca, mas a partilha, já que nessa transação ambos os envolvidos detêm a informação que foi objeto de informação (Dantas, 2006). Evidentemente, é preciso que a informação quando compartilhada perpasse pelos diferentes estágios de crescimento e amadurecimento vitais do saber para a participação do cidadão nas agendas públicas e políticas.

0 objetivo do trabalho com a informação é promover o desenvolvimento do indivíduo, de seu grupo e da sociedade. Entendemos por desenvolvimento de uma forma ampla, como um acréscimo de bem-estar, um novo estágio de qualidade de convivência, alcançado através da informação. A ação social maior é fazer a luz brilhar para cada ser humano através da informação como mediadora do conhecimento (Capurro, 2003, apudBarreto, 2002).

É fundamental ainda que esse gesto da nova partilha incentive a criação de políticas públicas nas localidades que articulam a educação e a gestão da comunidade, aos campos complementares abertos ao conhecimento e habilidades para a igualdade e integração social.

Por isso, convém destacar que, na contemporaneidade, houve uma mudança no eixo da valorização do conhecimento e da centralidade da comunicação. Cocco (2010) lembra que o modelo fordista era baseado na grande indústria e que 0 conhecimento utilizado fabricava um bem físico. 0 valor estava concentrado no bem material. No pós-fordismo, isto é, no capitalismo cognitivo atual, o conhecimento passa a produzir outro conhecimento por meio de propagação.

Os fins e os meios estão juntos e tornam-se incomensuráveis. Assim, o conhecimento novo pode agregar-se a um bem físico ou ser intangível (Issberner, 2010). Como consequência, perde-se o "padrão valor" (Cocco, 2010), já que o cálculo do investimento na produção não está centrado exclusivamente no tempo de trabalho, mas também no tempo de vida, produção e reprodução.

Issberner (apud Cocco, 2010) aponta que a produção de conhecimento por meio de conhecimento configura um caminho de aprendizagem que se propaga gerando sempre novas formas, versões e variações da base do conhecimento de onde se originou. 0 "novo conhecimento" não deve apenas reproduzir o seu imput (conhecimento anterior), mas voltar a gerar suas próprias premissas, reconstruindo as condições de um novo início do ciclo produtivo (Issberner, apud Cocco, 2010). 
Assim, defendemos que a informação, quando assimilada, transformada em conhecimento, possui mais que um valor econômico. Possui um valor político e social, como fonte de diversidade e flexibilidade. Alinhavada a essa perspectiva, propomos a metáfora da "informação laranja" para a informação que carrega em seu cerne o conceito vibrante da economia laranja.

\section{CONSIDERAÇÕES FINAIS}

A principal questão apontada pelo BID para o fomento da economia laranja é o acesso público às informações relacionadas à criatividade, arte e cultura. A cultura é aqui entendida como padrões de comportamento (Geertz, 1973) que permitem ao homem se exprimir, se situar no mundo, criar seu entorno e se comunicar.

Compreendemos que os sujeitos não só devem ter acesso à informação, o que reduziria o processo em uma mera teoria decisória, como produzir informação de qualidade. Pensamos na nova equação da partilha do valor da informação baseada na capacidade do falante e ouvinte de produzir informação.

Além disso, postulamos que esse pensamento parta da premissa da partilha do sensível, isto é, respeitando os dissensos, as resistências e a diversidade desde a sua produção, distribuição e uso do resultado.

Para nós, é isso que permite a oposição de um mundo comum ao outro, a disposição de objetos e imagens que formam um mundo consensual já dado ou a criação de situações a modificar nosso olhar e atitudes com relação ao ambiente coletivo. Por esta razão, Rancière (2010) critica o "mundo comum" sustentado pela racionalidade, pela universalidade e pelo consenso.

É interessante observar ainda que, na contramão do que discutimos, vêm os meios de comunicação que abordam o conflito social, por exemplo, como "problemas". Como analisamos, os dissensos são os únicos caminhos para a igualdade. Assim, destacamos a importância de repensar a maneira como a informação vem sendo partilhada, inclusive pela mídia tradicional.

Outro ponto que merece ser enfatizado, também por ser alvo de distorções, é em relação à cultura e à arte. A vida cultural do indivíduo não se faz apenas pelo do uso do chamado tempo livre e o gasto de dinheiro, mas em atitudes em períodos em que o que domina não parece ser cultural, como o tempo do trabalho, o do transporte, por exemplo. Por isso, conhecer as diversas faces do cotidiano é fundamental para a produção de informação e compartilhamento do tema.

Nesse sentido, as empresas possuem um papel fundamental nas indústrias criativas. Elas devem financiar a diversidade, apoiando novos coletivos em produção de bens para uso de todos. Mesmo quando se transferem responsabilidades para 0 setor privado, isso não exclui o papel regulador do Estado.

O Estado, é claro, deve desempenhar uma estratégia central nesse processo de divulgação, intervindo e preservando a informação enquanto bem público. Afinal, políticas eficazes implicam conhecimento, estratégias e formas de ação. E, nesse sentido, o esforço dos poderes públicos é insubstituível.

Por fim, entendemos que os poderes públicos sozinhos não dão conta da tarefa. Por isso, a dimensão da informação laranja que tentamos discutir aqui se refere a um conjunto diversificado de demandas profissionais, institucionais, políticas e econômicas, gerando, um circuito organizacional que estimula, por diversos meios, a produção, a circulação e o consumo de cultura, arte e criatividade. É sob essa lógica que compreendemos que a informação laranja, quando partilhada, leva cor à sociedade. 


\section{REFERÊNCIAS}

BARRETO, Aldo. A questão da informação. São Paulo em Perspectiva, Fundação Seade, v. 8, n. 4, p. 3-8, 1994. Disponível em: <http://aldoibct.bighost.com.br/ quest/quest2.pdf>. Acesso em: 23 maio 2015.

BUITRAGO RESTREPO, Felipe; DUQUE MÁRQUEZ, Iván. La economía naranja: una oportunidad infinita. Washington, DC: Banco Interamericano de Desarrollo, 2013. Disponível em: <http://www.iadb.org/es/noticias/anuncios/2013-10-30/laeconomia-nara nja-una-oportunidad-infinita,10622.html>. Acesso em: 15 jul. 2015.

CAPURRO, Rafael. Epistemologia e ciência da informação. Trad. de Ana Maria Rezende Cabral et al. In: ENCONTRO NACIONAL DE PESQUISA EM CIÊNCIA DA INFORMAÇÃO, V, Belo Horizonte, MG, 10 de novembro de 2003. Disponível em:<http://www. capurro.de/enancib_p.htm>. Acesso em: 10 jun. 2014.

COCCO, Giuseppe. Indicadores de inovação e capitalismo cognitivo. In. CENTRODEGESTÃOEESTUDOSESTRATÉGICOS. Bases conceituais em pesquisa, desenvolvimento e inovação: implicações para políticas no Brasil. Brasília, DF: Centro de Gestão e Estudos Estratégicos, 2010. p. 33-68. Disponível em: <http://www.cgee.org.br/atividades/redirect.php ?idProduto=64 03>. Acesso em: 26 maio 2014.

DANTAS, Marcos. Informação como trabalho e como valor. Revista da Sociedade Brasileira de Economia Política, Rio de Janeiro, n. 19, p. 44-72, 2006. Disponível em: <http://www.marcosdantas.com.br/conteudos/inf ormacao-como-trabalho-ecomo-valor-revista-da-sociedade-brasileira-de-economia-politica-n-19/. Acesso em: 23 maio 2015.

GEERTZ, Clifford. The interpretation of culture. Nova York: Basic, 1973.

HOWKINS, John. The creative economy. how people make money from ideas. Allen Lane: Penguin, 2001.

ISSBERNER, Liz-Rejane. Em direção a uma nova abordagem da inovação: coordenadas para o debate. In. CENTRO DE GESTÃO E ESTUDOS ESTRATÉGICOS. Bases conceituais em pesquisa, desenvolvimento e inovação: implicações para políticas no Brasil. Brasília, DF: Centro de Gestão e Estudos Estratégicos, 2010. p. 11-32. Disponível em: <http://www.cgee.org.br/ativ idades/redirect. php?idProduto=6403>. Acesso em: 23 maio 2015.

RANCIÈRE, Jacques. A partilha do sensível: estética e política. São Paulo: Exo/34. 2010.

UNESCO. Informe sobre la economía creativa (edicíon especial): ampliar los cauces de desarollo local, 2013. Disponível em:< http://www.unesco.org/culture/pdf/creative-economy-report-2013-es.pdf>. Acesso em: 29 de junho de 2015.

Artigo recebido em 31.7.2015 e aprovado em 19.11.2015. 